\title{
Формирование многослойных структур с интегрированными мембранами на основе пористого кремния
}

\author{
(C) В.В. Болотов, К.Е. Ивлев, Е.В. Князев, И.В. Пономарева , В.Е. Росликов \\ Омский научный центр Сибирского отделения Российской академии наук, \\ 644024 Омск, Россия \\ ฯ E-nail: poni@obisp.oscsbras.ru
}

Поступила в Редакцию 24 декабря 2019 г.

В окончательной редакции 28 декабря 2019 г.

Принята к публикации 30 декабря 2019 г.

\begin{abstract}
Получены многослойные интегрированные пористые мембраны в монолитном обрамлении, содержащие пористый кремний двух типов: макропористый с диаметрами пор до 10 мкм, канальный с диаметрами каналов от 100 до 300 нм. Предложена лабораторная технология получения двухслойных структур макропористый/канальный кремний с использованием подложек высокоомного $n$ - $\mathrm{Si}(1 \mathrm{OM} \cdot \mathrm{cm})$. Обсуждается механизм порообразования и его влияние на морфологию пористых слоев для электролитов с использованием муравьиной кислоты и гидроксида аммония.
\end{abstract}

Ключевые слова: пористый кремний, электрохимическое травление, электронная микроскопия, многослойные структуры, мембраны.

DOI: $10.21883 /$ FTP.2020.05.49269.9340

\section{1. Введение}

Кремниевые пористые материалы находят широкое применение в современной микроэлектронике, обладая чрезвычайно развитой поверхностью и возможностью встраивания в отработанную кремниевую технологию производства микроэлектронных компонентов [1-3].

Характеристики развитой поверхности пористого кремния могут варьироваться при электрохимических обработках в широких пределах. Размер пор, пористость, геометрия каналов - три параметра, контролируемые условиями анодирования, легированием подложки и составом электролита [4].

Применение пористых кремниевых мембран в газовых сенсорах на основе гибридных и композитных материалов повышает избирательность чувствительных элементов $[5,6]$. Использование кремниевых мембран со сквозными каналами открывает широкие перспективы их практического применения в качестве микро- и нанофильтров $[2,7,8]$.

Весьма перспективной является задача получения многоуровневых структур со слоями различной морфологии, т.е. с разными размерами пор, пористостью, геометрией каналов, полученных на одной подложке.

Однако получение пористого кремния с существенно различающимися размерами пор на одной подложке имеет ряд ограничений. На подложках сильнолегированного $n^{+}$-Si (0.01 Ом·см) можно формировать структуры с диаметрами сквозных каналов до $100 \mathrm{Hм} \mathrm{с}$ использованием перекиси водорода как окислителя в составе фторсодержащих растворов [9,10]. В работе [11] авторы применили электролит, содержащий плавиковую кислоту и ТМАН (тетраметиловый гидроксид аммония, $\left.\left(\mathrm{CH}_{3}\right)_{4} \mathrm{NOH}\right)$, и электрохимическим травлением получили на $n^{+}-\mathrm{Si}(0.02-0.06$ Ом $\cdot \mathrm{cm})$ поры диаметром $\sim 600$ нм. Однако ТМАН является чрезвычайно токсичным. Получение макропор размером > 1 мкм на $n^{+}$-Si не описано. Таким образом, на $n^{+}-\mathrm{Si}$ невозможно получить многослойные пористые структуры с диаметрами $>1$ мкм.

Для получения многослойных структур с интегрированными мембранами, включающих слои макропористого кремния с поперечными размерами пор $>1$ мкм и слои от $100 \mathrm{Hм}$, в едином технологическом процессе необходимо использование высокоомного кремния $[12,13]$. Слои макропористого кремния с диаметрами пор от 800 нм служат структурой с развитой поверхностью для чувствительного материала наноструктурированного окисла металла [5,14-18].

С целью создания многослойных сенсорных структур была разработана лабораторная технология получения двухслойных структур макропористый/канальный кремний с использованием подложек $n$-Si с более высоким удельным сопротивлением (1 Ом·см) с целью формирования верхнего слоя с диаметром пор > 1 мкм для дальнейшего высаживания чувствительного элемента. В качестве фильтрующего слоя создавался слой канального кремния с размером каналов 100-300 нм.

\section{2. Получение монолитных интегрированных структур со слоями канального кремния}

Структуры со сквозными каналами формировались на пластинах кремния толщиной 380 мкм, легированных фосфором с удельным сопротивлением 1 Ом · см с кристаллографической ориентацией поверхности (100). Канальный кремний был получен анодным травлением в двухкамерной электрохимической ячейке [19] в электролите состава $\mathrm{HF}(42 \%): \mathrm{HCOOH}:\left(\mathrm{CH}_{3}\right)_{2} \mathrm{CO}=1: 1: 1$. 
Ацетон добавлялся в качестве поверхностно-активного вещества. Плотность тока $j$ варьировалась в пределах от 200 до $400 \mathrm{MA} / \mathrm{cm}^{2}$. Без добавления ацетона ток $>100 \mathrm{MA} / \mathrm{cm}^{2}$ приводил к отслоению пористого слоя. В камере с тыльной стороны пластины в качестве электролита применялся $\mathrm{NH}_{4} \mathrm{OH}(5 \%)$.

Морфология образцов исследовалась с использованием растрового электронного микроскопа (РЭМ) JEOL JSM-6610-LV. Как видно из рис. 1, формируемые структуры имеют вертикальные каналы, от которых исходят боковые поры нормально к первым.

По РЭМ-изображениям изготовленных образцов (рис. 1) измерялись размеры каналов и с помощью программного комплекса ImageJ оценивалась плотность каналов. Полученные структуры имели широкое распределение каналов по размерам (рис. 2). Учитывая, что пористость $p$ определяется как объем каналов, имеющих
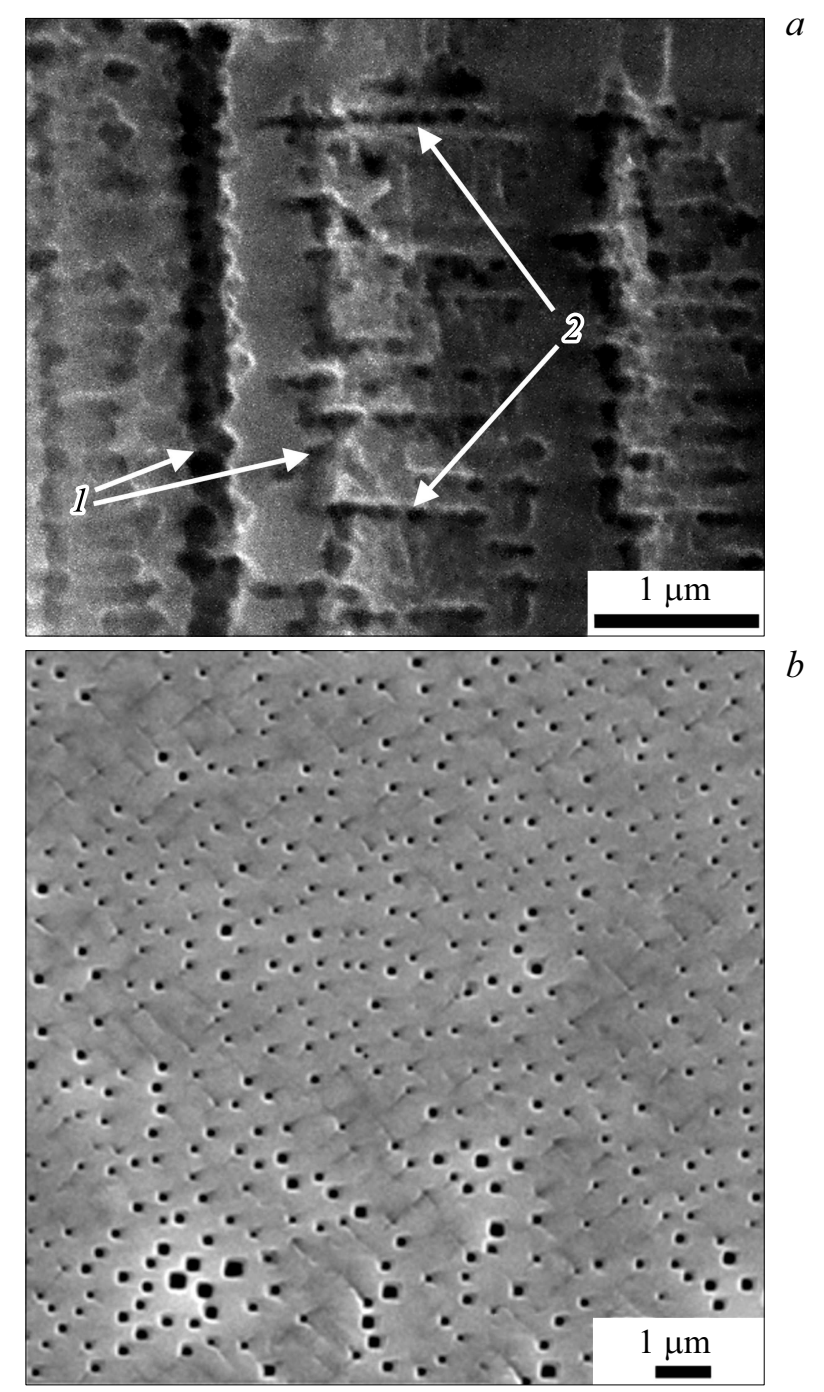

Рис. 1. РЭМ-изображения канального кремния, полученного в электролите $\mathrm{HF}: \mathrm{HCOOH}:\left(\mathrm{CH}_{3}\right)_{2} \mathrm{CO}=1: 1: 1$ при плотности тока $300 \mathrm{MA} / \mathrm{cm}^{2}: a-$ поперечное сечение $(1-$ магистральные каналы, $2-$ боковая пора); $b-$ вид сверху (после ионного распыления поверхности).

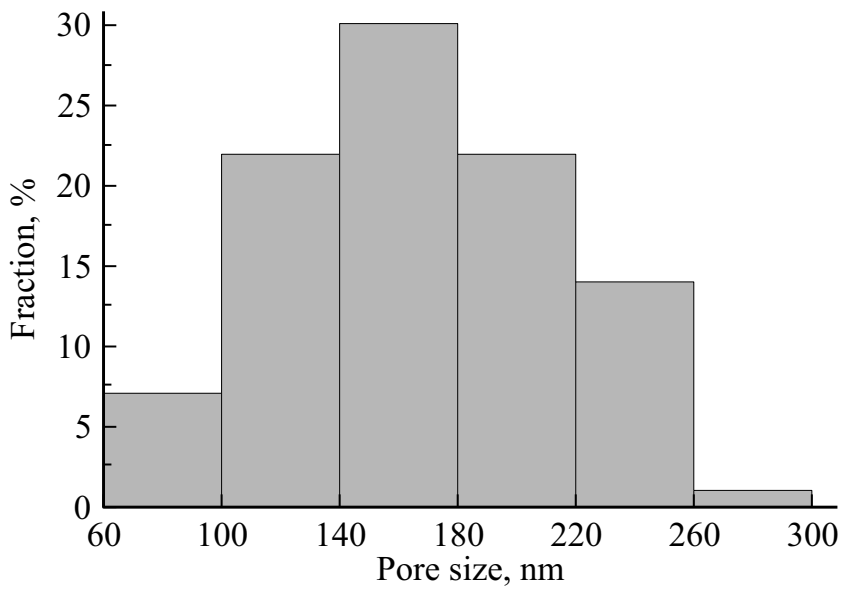

Рис. 2. Распределение каналов по размерам для образца, полученного в электролите $\mathrm{HF}: \mathrm{HCOOH}:\left(\mathrm{CH}_{3}\right)_{2} \mathrm{CO}=1: 1: 1$ при плотности тока $300 \mathrm{MA} / \mathrm{cm}^{2}$.

почти квадратное сечение (рис. $1, b$ ), отнесенный к общему объему канального слоя, а также учитывая распределение каналов по размерам, $p$ вычисляли следующим образом:

$$
p=n \overline{D^{2}}=n\left(\bar{D}^{2}+\sigma^{2}\right),
$$

где $n-$ плотность каналов, $\overline{D^{2}}-$ средняя площадь каналов, $\bar{D}^{2}-$ квадрат среднего значения поперечного размера каналов, $\sigma$ - стандартное отклонение поперечного размера каналов.

Режимы получения канального кремния и морфологические параметры, рассчитанные по формуле (1), представлены в табл. 1.

Для формирования мембраны на основе двухслойной структуры макропористый/канальный кремний на кремниевую пластину наносили маску на основе лака ХВ-784, устойчивую к травителю СР-4A и используемым электролитам. Через окна размером $5 \times 5 \mathrm{Mм}^{2}$ в маске с помощью СР-4А состава $\mathrm{HF}: \mathrm{CH}_{3} \mathrm{COOH}: \mathrm{HNO}_{3}=1: 2.5: 4$ пластина кремния утончалась до толщины 50-100 мкм.

Затем на пластине со вскрытыми окнами формировали верхний макропористый слой. Для анодного травления верхнего слоя использовался электролит состава $\mathrm{HF}(42 \%): \mathrm{NH}_{4} \mathrm{OH}(30 \%)=1: 4$ и плотности тока $4-10 \mathrm{MA} / \mathrm{cm}^{2}$. Травление верхнего макропористого слоя проводилось в однокамерной ячейке при освещении от лампы накаливания мощностью 95 Вт, которая размещалась на расстоянии $12 \mathrm{~cm}$ над пластиной кремния. Компоненты электролита вступают в химическую реакцию с образованием фторида аммония и воды, причем при данном соотношении $\mathrm{pH}$ близок к нейтральному. Омический контакт обеспечивался нанесением на тыльную сторону пластины кремния InGa-эвтектики. Примененный нами электролит на основе $\mathrm{NH}_{4} \mathrm{~F}$ аналогичен по химическим свойствам описанному в работе [11] 
Таблица 1. Режимы анодирования и размерные характеристики канального кремния, полученного в двухкамерной ячейке

\begin{tabular}{c|c|c|c|c|c}
\hline Электролит & $\begin{array}{c}j, \\
\text { мА/см }\end{array}$ & $\begin{array}{c}\text { Диаметр каналов, } \\
\text { нм }\end{array}$ & $\begin{array}{c}\text { Стандартное отклонение } \\
\text { размеров каналов, нм }\end{array}$ & $\begin{array}{c}\text { Плотность каналов, } \\
10^{8} \mathrm{~cm}^{-2}\end{array}$ & $\begin{array}{c}\text { Пористость, } \\
\%\end{array}$ \\
\hline $\mathrm{HF}: \mathrm{HCOOH}:\left(\mathrm{CH}_{3}\right)_{2} \mathrm{CO}$ & 200 & 195 & 37 & 2.2 & 9 \\
$1: 1: 1$ & & 164 & 47 & 3.1 & 9 \\
$\mathrm{HF}: \mathrm{HCOOH}:\left(\mathrm{CH}_{3}\right)_{2} \mathrm{CO}$ & 300 & 214 & 122 & 2.8 & 17 \\
$\mathrm{HF}: \mathrm{HCOOH}:\left(\mathrm{CH}_{3}\right)_{2} \mathrm{CO}$ \\
$1: 1: 1$
\end{tabular}

электролиту на основе плавиковой кислоты и ТМАН, кроме того является нетоксичным.

На следующем этапе пластина с полученным верхним макропористым слоем очищалась от InGa-контакта, промывалась водой и помещалась в двухкамерную ячейку для формирования нижнего канального слоя в электролите $\mathrm{HF}: \mathrm{HCOOH}:\left(\mathrm{CH}_{3}\right)_{2} \mathrm{CO}$ (см. табл. 1). В двухкамерной электрохимической ячейке анодное травление кремния проводилось до тех пор, пока каналы не достигали обратной стороны пластины. Из-за краевого эффекта это происходит не по всей площади, а вблизи края окна в маске, после чего ток начинает протекать преимущественно через сквозные каналы и скорость травления резко падает. При плотности тока $200 \mathrm{MA} / \mathrm{cm}^{2}$ скорость травления составляет $\sim 1.5$ мкм/мин. Оставшийся монокристаллический кремний с тыльной стороны удалялся распылением пучком ионов $\mathrm{Ar}^{+}$с энергией 5 кэВ и плотностью пучка $9.6 \cdot 10^{16} \mathrm{c}^{-1} \cdot \mathrm{cm}^{-2}$.

Данный метод получения был разработан для увеличения эффективной площади мембран, чего сложно достичь при получении мембран механическим утончением [20]. В работе [20] показан способ получения газопроницаемых мембран на сильнолегированном $n$-Si c характерными параметрами: диаметр пор 90 нм, плотность каналов $(1.0-1.5) \cdot 10^{10} \mathrm{~cm}^{-2}$, пористость $\sim 50 \%$, диаметр окна пористого кремния 0.3-0.4 мм. Данной площади мембраны недостаточно для пористости до $20 \%$, плотности каналов $\sim 10^{8} \mathrm{~cm}^{-2}$, характерных при получении макропористых слоев на высокоомном $n$-Si [21], так как эффективная площадь, оцениваемая как площадь окна, умноженная на пористость, в случае $n^{+}$-Si равна $8 \cdot 10^{-4} \mathrm{~cm}^{2}$. В данной работе эффективная площадь мембран достигает $\sim 4 \cdot 10^{-2} \mathrm{~cm}^{2}$.

\section{3. Структурные характеристики многослойных структур с интегрированными мембранами на основе пористого кремния}

На рис. 3,4 представлены РЭМ-изображения двухслойной структуры макропористый/канальный кремний. В табл. 2 представлены размеры макропор в зависимости от плотности тока. При продолжительности травления 2 ч и плотности тока $5 \mathrm{MA} / \mathrm{cm}^{2}$ толщина макропористого слоя составляет $\sim 15$ мкм. Плотность макропор

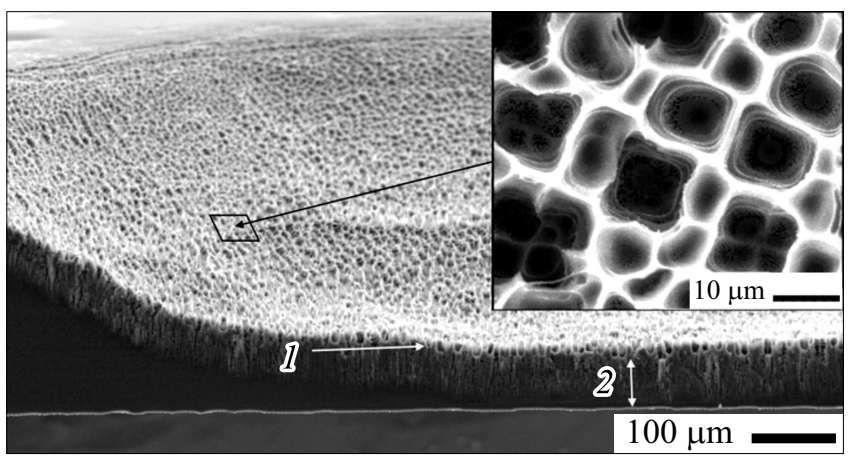

Рис. 3. РЭМ-изображение поперечного сечения мембраны двухслойного пористого кремния: 1 - макропористый слой, 2 - канальный слой. На вставке - вид сверху фрагмента в увеличенном масштабе.

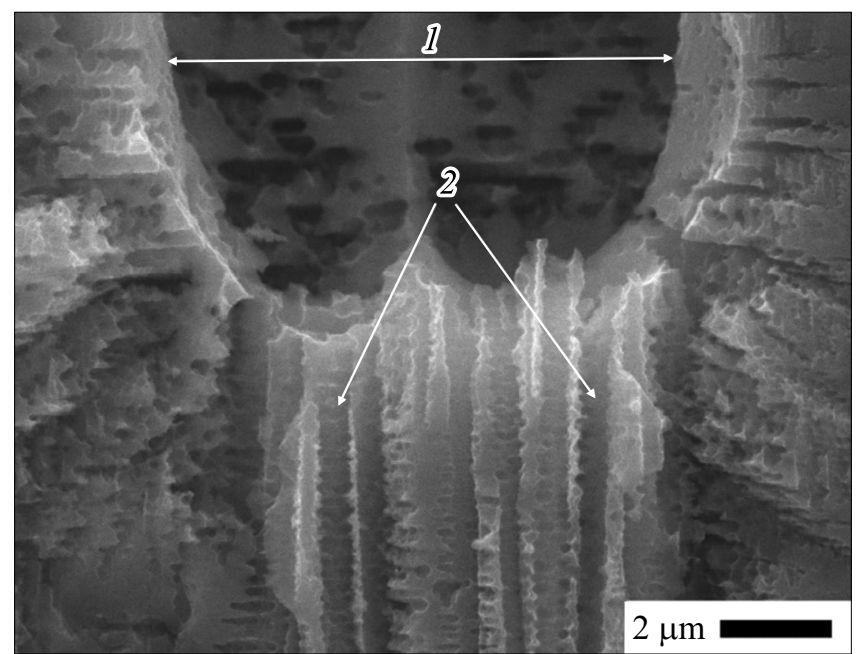

Рис. 4. РЭМ-изображение дна макропоры: 1 - макропора, 2 - каналы.

слабо зависит от плотности тока и составляет величину $\sim 1.5 \cdot 10^{6} \mathrm{~cm}^{-2}$. Таким образом, на одну макропору приходится $\sim 100$ каналов в нижележащем слое канального кремния.

Размеры каналов в нижележащем слое соответствуют приведенным в табл. 1. От каналов исходят боковые поры, ориентированные нормально по отношению к 
Таблица 2. Поперечные размеры макропор в верхнем слое в зависимости от плотности тока

\begin{tabular}{c|c}
\hline$j, \mathrm{MA} / \mathrm{cm}^{2}$ & Диаметр макропор, мкм \\
\hline 4 & 6.9 \\
5.6 & 8.6 \\
10 & 9.9
\end{tabular}

Таблица 3. Средние величины толщины стенок между каналами в зависимости от плотности тока для электролита $\mathrm{HF}: \mathrm{HCOOH}:\left(\mathrm{CH}_{3}\right)_{2} \mathrm{CO}=1: 1: 1$

\begin{tabular}{c|c}
\hline$j, \mathrm{мA} / \mathrm{cm}^{2}$ & Толщина стенок, нм \\
\hline 200 & 480 \\
300 & 400 \\
400 & 390
\end{tabular}

первым так же, как и в случае однослойных канальных образцов. Длина боковых пор определяется расстоянием между каналами и не превышает половину этого расстояния. Средние величины толщины стенок между каналами приведены в табл. 3. Диаметр боковых пор лежит в пределах от 70 до 160 нм.

Носители заряда дырки необходимы для электрохимического растворения кремния. В пластинах кремния с электронным типом проводимости дырки являются неосновными носителями заряда. Вследствие сорбции на поверхности кремния ионов водорода, которые захватывают электрон из валентной зоны $[1,22]$, в приповерхностной области повышается концентрация дырок:

$$
\mathrm{H}_{\mathrm{ad}}^{+} \rightarrow h^{+}+\mathrm{H}_{\mathrm{ad}}
$$

где $\mathrm{H}_{\mathrm{ad}}^{+}$- ион водорода, адсорбированный из электролита на поверхности кремния, $h^{+}$- дырка, $\mathrm{H}_{\mathrm{ad}}-$ адсорбированный на поверхности кремния атом водорода в нейтральном состоянии. Это объясняет, почему в присутствии окислителей возможно электрохимически растворять электронный кремний без освещения. Электролит на основе фторида аммония имеет нейтральный показатель $\mathrm{pH}$, поэтому для обеспечения растворения кремния в нем необходимо генерировать дырки с помощью освещения.

Теории зарождения пор на пластинах $n$-Si основываются на предположении, что в локальных участках поверхности кремния происходит электрический пробой, и для объяснения морфологии с образованием боковых ответвлений привлекается модель токовых вспышек (currentburst model) [23-25].

Согласно модели области пространственного заряда (ОП3) [26,27], размеры стенок пор должны коррелировать с шириной ОПЗ. ОПЗ определяется уровнем легирования, состоянием поверхности и внешним напряжением. Из табл. 3 видно, что с увеличением плотности тока и соответственно напряжения толщина стенок уменьшается. Также видно, что в электролите с муравьиной кислотой эта толщина < 1 мкм, что значительно меньше удвоенной теоретической ширины ОПЗ, которая для используемых подложек $n$-Si с удельным сопротивлением $\sim 1$ Ом $\cdot$ см составляет несколько микрометров [24]. Данный механизм порообразования, описываемый моделью ОПЗ, не является основным при использовании органических электролитов [24,25,27].

Органические растворы НF обладают низкой окислительной способностью, в результате образование оксида кремния при анодировании сильно подавлено и происходит реакция прямого растворения кремния $[27,28]$. Каналы в нижележащем слое имеют почти квадратное сечение (рис. $1, b)$, что говорит о реакции прямого растворения $\mathrm{Si}$ [24]. Важным фактором, влияющим на образование пор, является водородная пассивация. Водородная пассивация различается для плоскостей с разной кристаллографической ориентацией и определяет преимущественное направление роста пор. Органические электролиты обладают низкой способностью к пассивации из-за медленной адсорбции водорода, которая легко нарушается, что приводит к появлению боковых пор $[27,28]$.

В связи с этим можно сделать вывод, что при использовании муравьиной кислоты в составе электролита, высоких плотностях тока тенденцию роста боковых пор сложно подавить, - характерный эффект для структур, полученных с использованием органических электролитов $[24,25,27,28]$.

\section{4. Электрофизические измерения}

Полученные структуры мембран на канальном кремнии исследовались на пропускание газа $\mathrm{NO}_{2}$ при комнатной температуре. Для этого сравнивали отклик резистивного газочувствительного элемента, подавая в измерительную камеру одинаковое количество газа через канальную мембрану и напрямую. Сопротивление резистивного газочувствительного элемента оценивалось из линейных вольт-амперных характеристик, которые измерялись с помощью LCR meter Agilent E4980A. Отклик $S$ сенсорного элемента рассчитывался как

$$
S=\frac{R_{g}-R_{a}}{R_{a}}
$$

где $R_{g}$ - сопротивление элемента после экспозиции в газе, $R_{a}$ - начальное сопротивление элемента до экспозиции в газе. В качестве газочувствительного элемента использовалась пленка $\mathrm{SnO}_{x}$ на ситалловой подложке, полученная методом газофазного осаждения, описанного в [29].

Результаты тестирования на газопропускание канальной мембраны представлены на рис. 5.

Тестирование на газопропускание канальной мембраны толщиной $\sim 50$ мкм и с размером каналов в самом узком месте $\sim 200$ нм показало, что наличие канальной мембраны уменьшает отклик сенсорного элемента к одинаковым дозам $\mathrm{NO}_{2}$ на 50-60\%. Таким образом, 


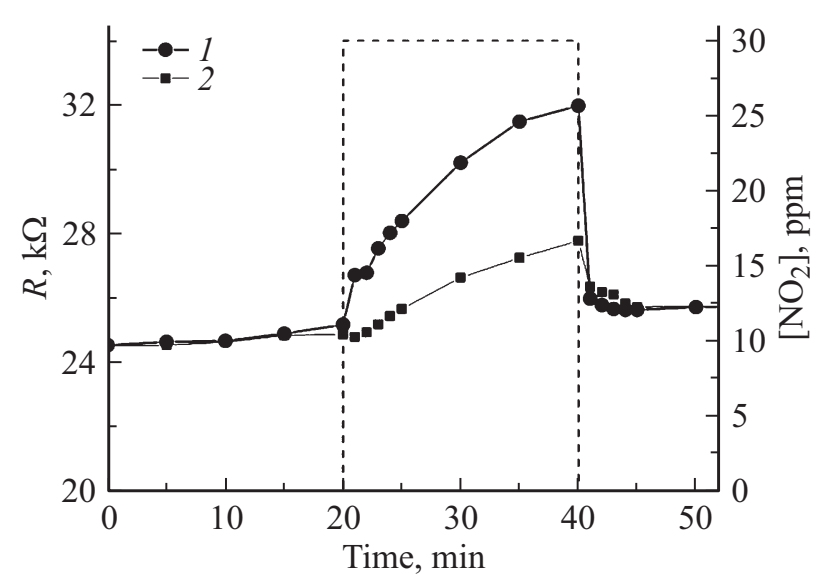

Рис. 5. Изменение сопротивления $R$ газочувствительного элемента: 1 - при адсорбции $\mathrm{NO}_{2}$ без мембраны, 2 - после прохождении $\mathrm{NO}_{2}$ через мембрану. Штриховая линия подаваемый импульс $\mathrm{NO}_{2}$.

можно сделать вывод, что газ частично сорбируется на стенках каналов и полностью не проходит через мембрану, которую можно использовать в качестве фильтра.

\section{5. Заключение}

Разработана лабораторная технология получения двухслойных структур макропористый/канальный кремний с использованием подложек высокоомного $n$-Si $(1 \mathrm{OM} \cdot \mathrm{cm})$.

Получены многослойные интегрированные пористые мембраны в монолитном обрамлении, содержащие пористый кремний двух типов: макропористый с диаметрами пор до 10 мкм, канальный с диаметрами каналов от 100 до 300 нм. Проведенные электрофизические измерения показали, что диоксид азота частично сорбируется в данных мембранах.

\section{Финансирование работы}

Работа выполнена по государственному заданию Омского научного центра СО РАН в соответствии с Программой ФНИ ГАН на 2013-2020 годы (номер государственной регистрации проекта в системе ЕГИСУ НИОКТР АААА-А17-117041210227-8). В работе было использовано оборудование Омского регионального центра коллективного пользования СО РАН.

\section{Конфликт интересов}

Авторы заявляют, что у них нет конфликта интересов.

\section{Список литературы}

[1] C. Cozzi, G. Polito, K.W. Kolasinski, G. Barillaro. Adv. Funct. Mater., 27, 1604310 (2017).

[2] T. Pichonat, B. Gauthier-Manuel. J. Membrane Sci., 280, 494 (2006).
[3] R.W. Tjerkstra, J.G.E. Gardeniers, J.J. Kelly, A. van den Berg. J. Microelectromechanical Systems, 9 (4), 495 (2000).

[4] M.J. Sailor. Porous Silicon in Practice: Preparation, Characterization and Applications (Weinheim, Wiley-VCH, 2012).

[5] R. Angelucci, A. Poggi, L. Dori, G.C. Cardinali, A. Parisini, A. Tagliani, M. Mariasaldi, F. Cavani. Sensors Actuators, 74, 95 (1999).

[6] L. Velleman, C.J. Shearer, A.V. Ellis, D. Losic, N.H. Voelcker, J.G. Shapter. Nanoscale, 2, 1756 (2010).

[7] A. Kovacs, A. Kovacs, M. Pogany, U. Mescheder. Sensors Actuators B, 127, 120 (2007).

[8] A. Kovacs, U. Mescheder. Sensors Actuators B, 175, 179 (2012).

[9] D.H. Ge, J.W. Jiao, S. Zhang, Y.L. Wang. Electrochem. Commun., 12, 603 (2010).

[10] D.H. Ge, M.C. Wang, W.J. Liu, S. Qin, P.L. Yan, J.W. Jiao. Electrochim. Acta, 88, 141 (2013).

[11] M. Christophersen, J. Carstensen, H. Foll. Phys. Status Solidi A, 182, 45 (2000).

[12] Е.В. Астрова, А.А. Нечитайлов, А.Г. Забродский. Альтернативная энергетика и экология: междунар. науч. журн., 2 (46), 60 (2007).

[13] В.А. Юзова, Ф.Ф. Меркушев, О.В. Семенова. Письма ЖТФ, 43 (16),79 (2017).

[14] R. Angelucci, A. Poggi, L. Dori, G.C. Cardinali, A. Parisini, G. Pizzochero, F. Trifiro, F. Cavani, C. Critelli, L. Boarino. Thin Sol. Films, 297, 43 (1997).

[15] T.V.K. Karthik, L. Martinez, V. Agarwal. J. Alloys Compd., 731, 853 (2018).

[16] W. Laminack, N. Pouse, J.L. Gole. ECS J. Solid State Sci. Technol., 1 (2), Q25 (2012).

[17] C. Baker, W. Laminack, J.L. Gole. J. Appl. Phys., 119, 124506 (2016).

[18] В.В. Болотов, В.Е. Росликов, Е.А. Росликова, К.Е. Ивлев, Е.В. Князев, Н.А. Давлеткильдеев. ФТП, 48 (3), 412 (2014).

[19] С.П. Зимин, М.Н. Преображенский, Д.С. Зимин. Письма ЖТФ, 26 (1), 24 (2000).

[20] В.В. Болотов, К.Е. Ивлев, Е.В. Князев, И.В. Пономарева, В.Е. Росликов. Патент РФ № 2690534 C1 (2019).

[21] E. Galun, C. Reuben, S. Matlis, R. Tenne, C. Levy-Clement. J. Phys. Chem., 99, 4132 (1995).

[22] Г.В. Ли, Е.В. Астрова, А.И. Лихачев. ФТП, 52 (13), 1614 (2018).

[23] J. Carstensen, M. Christophersen, H. Foll. Mater. Sci. Engin. B, 69-70, 23 (2000).

[24] X.Q. Bao, J.W. Jiao, Y.L. Wang, K.W. Na, H. Choi. J. Electrochem. Soc., 154 (3), D175 (2007).

[25] M. Christophersen, J. Carstensen, S. Rönnebeck, C. Jager, W. Jager, H. Foll. J. Electrochem. Soc., 148 (6), E267 (2001).

[26] V. Lehmann, H. Foll. J. Electrochem. Soc., 137 (2), 653 (1990).

[27] H. Foll, M. Christophersen, J. Carstensen, G. Haase. Mater. Sci. Engin. R, 39, 93 (2002).

[28] Е.В. Астрова, Н.Е. Преображенский, Г.В. Ли, С.И. Павлов. ФТП, 52 (3), 414 (2018).

[29] V.V. Bolotov, P.M. Korusenko, S.N. Nesov, S.N. Povoroznyuk, V.E. Roslikov, E.A. Kurdyukova, Yu.A. Sten'kin, R.V. Shelyagin, E.V. Knyazev, V.E. Kan, I.V. Ponomareva. Mater. Sci. Engin. B, 177, 1 (2012).

Редактор Л.В. Шаронова 


\section{Formation of multilayer structures with integrated membranes based on porous silicon}

\section{V.V. Bolotov, K.E. Ivlev, E.V. Knyazev,} I.V. Ponomareva, V.E. Roslikov

Omsk Scientific Center,

Siberian Branch of Russian Academy of Sciences,

644024 Omsk, Russia

Abstract Multilayer integrated porous membranes in a monolithic frame were obtained. Porous membranes consist of macroporous silicon with pore diameters of up to $10 \mu \mathrm{m}$ and channel silicon with channel diameters from 100 to $300 \mathrm{~nm}$. A laboratory technology is proposed for formation of macroporous/channel silicon two-layer structures using high-resistance $n$-Si substrates $(1 \Omega \cdot \mathrm{cm})$. The mechanism of pore formation is discussed and how this mechanism affects the morphology of porous layers when formic acid and ammonium hydroxide are used as electrolytes. 